\title{
Trends in Experimental High-Energy Physics
}

T. W. L. Sanford*

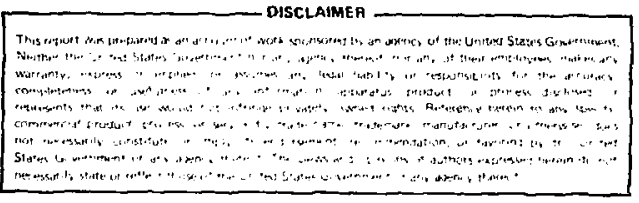

*Sandia National Laboratories. Albuquerque. NM B7 185.

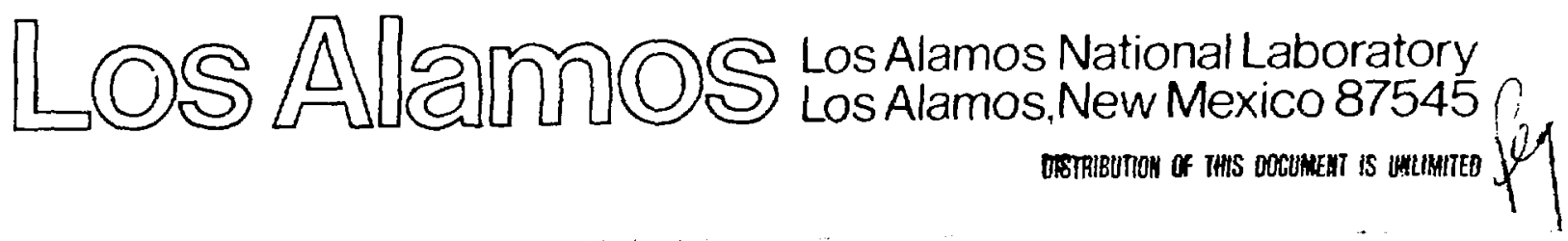


TRENDS IN EXPERIMENTAL HIGH-ENERGY PHYSICS

by

T. W. L. Sanford *

\section{ABSTRACT}

Data from a scan of papers in Physical Review Letters and Physical Review are used to demonstrate that American high-energy physicists show a pattern of accelerator and instrumentation usage characteristic of that expected from the logistic-substitution mode1 of Marchetti and of Fischer and Pry.
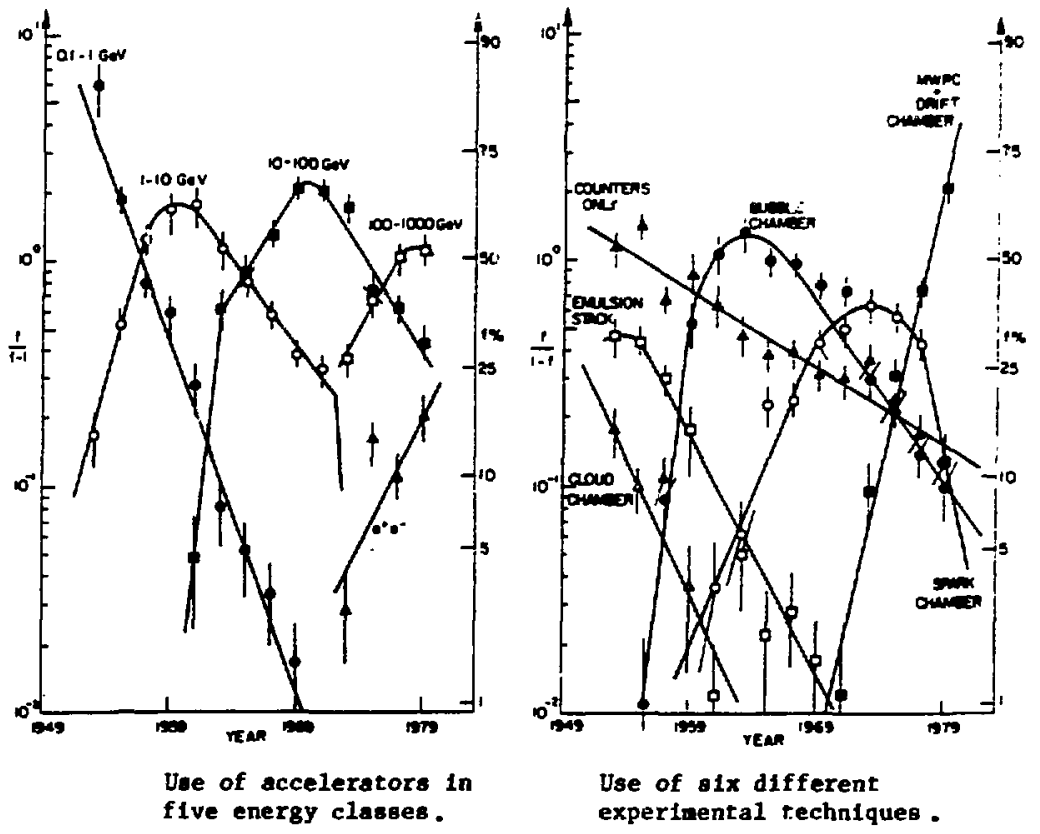

*Invited lecture at the 8th Cracow-Munich High-Energy Physics Seminar, Cracow, Poland, April 1981. 


\section{INTRODUCTION}

The first machines capable of producing mesons were cyclotrons. As accelerators of higher energy were developed, physicist.s transferred their work to these machines, which enabled the frontiers of small distances and high-mass states to be explored more easily. Today most of the experimental effort in high-energy physics (HEP) is taking place at the large national accelerator laboratories.

Paralleling the development of accelerators, instruments for detecting high-energy collisions have evolved. Initially, counters, emulsion stacks, and cloud chambers were used; but as it became necessary to look at large statistical samples of data with better spatial precision and better knowledge of particle type, these detectors were replaced. At present, for example, the multiwire proportional chamber (MWPC) is widely used.

Similarly, owing to new technology, ease of use, and greater availability, man has switched from wood to coal and from coal to oil and gas as primary sources of energy. Marchetti demonstrated that the transition from one source to the next in this series proceeded at a we11-defined rate, independent of major events such as war or economic depression. 1-3 Also, Fischer and Pry showed earlier that a smooth transition takes piace between competing technologies, such as that between open-hearth and Bessemer steel or between electric arc and open-hearth steel. 4

The success of their analyses in the field of energy raises an exciting question; namely, can a similar analysis be employed to describe the use of different particle accelerators and experimental techniques by physicists? of so, then what are the individual growth and decay rates? Do any patterns emerge? And can extrapolations give us meaningful projections as to future trends?

To be able to answer these questions with respect to the community of American experimental high-energy physicists, the papers in Physical Review Letters (PRL) were scanned. The type of machine and the instruments being used for an experiment were recorded.

Underlying this approach was the assumption that the number of papers generated by experimenters usiig a given machine and a given type of instrument is representative of the usage of that accelerator and of that instrumentation.

PRL was chosen for two reasons: (1) it is the principal journal where frontier research is published in America, and (2) its physical size is small. The latter point was important because the CERN and DESY computer files of HEP papers go back only to 1970 , which meant that a manual search was required in order to investigate earlier periods.

PRL was first published in July 1958. Because the initial search proved interesting, the Physical Review journal was used to extend the study back to 1953, the year that the Cosmotron began to operate and compete with cyclotrons.

In the following, the logistic-substitution mode1 of Marchetti and of Fischer and Pry is briefly described and the results of the scan are presented.

\section{LOGISTIC-SUBSTITUTION MODEL}

The analysis by the above authors is based on a differential equation. It assumes that the fractional rate at which a new commodity enters a market is proportional not only to the fraction itself but also to the fraction of the market not yet covered:

$$
\frac{\mathrm{df}}{\mathrm{dt}}=\alpha \cdot \mathrm{f} \cdot(1-\mathbf{f})
$$


The solution of this equation has the form

$$
n(t)=\frac{f(t)}{1-f(t)}=e^{\alpha t+\beta},
$$

which implies that the growth of the commodity proceeds at a rate defined by $x$, when $\ln [n(t)]$ is considered to be a function of time t.

The growth of a given commodity along a logistics curve is arrested and its slope changes only when a new commodity begins to penetrate the market. Consider the case where the commodity described by $f$ has now saturated the market and where a new commodity described by $\bar{f}$ is capturing the market at the rate given by $\alpha^{\prime}$ with intercept $B^{\prime}$. The commodity that originally exhausted the market then declines logistically at the same rate as that at which the new commodity is expanding:

$$
\frac{f}{1-f}=\frac{1-\bar{f}}{\bar{f}}=e^{-\left(\alpha^{\prime} t+\beta^{\prime}\right)}
$$

The model does not predict anything about the rates of increase or decrease but states only that, in the variable in $(n)$, the rate of shange is linear.

For small f, the equations reduce to those governing exponential growth. Pure exponential expansion in $f$ has no limit, whereas the physical $f$ can be no larger than $100 \%$. The preceding differential equation thus assumes that not only is the rate of change in $f$ proportional to $f$, as in exponential growth, but also that the change is proportional to the space into which $f$ can expand.

\section{RESULTS OF THE SCAN}

A total of 2165 papers was scanned for the period from January 1953 to July 1980. Two-year bins were chosen so as to minimize statistical fluctuations. This size was small enough, however, to be sensitive to major changes in usage.

The fractional usage of a given accelerator was defined as being

$$
\mathrm{f}=\frac{\mathrm{M}}{\mathrm{M}+\mathrm{N}} \text {, }
$$

where $M$ was the number of papers arising from experiments performed on a given machine and $N$ was the number of papers arising from experiments performed on all other machines. The statistical uncertainty in $M$ and $N$ was taken to be the square root of the respective number. 
These errors resulted in an error in $\eta$ of:

$$
\Delta n=\sqrt{\frac{(M+N) \cdot M}{N^{3}}}
$$

Typically 150 HEP papers were written in PRL every two years. Accordingly, the uncertainty in $\eta$ for this period was about $16 \%$ for a machine whose usage was $50 \%$ of the total (Figs. 1 and 2).

\section{A. Accelerator Usage}

Over the past 30 years, at least 31 machines have been constructed on which Americans have mounted HEP experiments. 5 $^{-9}$ Many of these accelerators are now dismantled. Consequently the situation is more complicated than it is for the field of energy, where there are fewer than 10 primary sources to consider. In addition, the sinall data sample limits our ability to look at individual machines with low usage.

Nonetheless, the machines can be grouped into classes. The six synchrocyclotrons, the four electron synchrotrons, the one betatron, and the one electron linac of Table I were all constructed circa 1950. Many of these accelerators continued to be used through the early 1970s. They nearly all have enough energy to produce pions and muons, but not enough energy to generate strange mesons and baryons. The decline in the use of these machines for HEP clearly demonstrates logistic behavior over three decades in the variable $n$ (Fig. 3). An exponential fit to the data gives a $x^{2}$ of 5.8 for 7 Dof (degrees of freedom) with a decay time of $6.5 \pm 0.4$ years (Table II). Here decay time is taken to be the length of time required for the fractional usage to decrease from $50 \%$ to about $10 \%$, or for $n$ to change by a factor of 10 .

From the late 1950 s unt 11 now, three accelerators have been in dominant use. They are the $6.2-\mathrm{GeV}$ Lawrence Berkeley Laboratory proton synchrotron (Bevatron), the 33- GeV Brookhaven National Laboratory Alternating-Gradient synchrotron (AGS), and the 500-GeV Fermi National Accelerator Laboratory (FNAL) synchrotron. The use of these accelerators also shows logistic behavior (Figs. 4 and 5). If the other machines of this era are examined, it can be seen in particular that from the date when the first beam was produced, it took only about 6 years for a given accelerator to attain its maximum impact, but that it took about 14 years for the usage to decrease from $50 \%$ to $10 \%$ (Table II).

In order that an overview of accelerator usage could be made, the machines were grouped according to the energy decade into which their beam energy fell (Fig. 5 and Table I). In each of these decades, new areas of physics were opened.

The rapid initial rise of the $10-$ to $100-\mathrm{GeV}$ decade was due to the start-up of the AGS. The continued slower rise of $11 \pm 2$ years, however, was due to the use of the other accelerators of that decade. The slower rise is characteristic of the rise time of $9.3 \pm 2.2$ years of. the $100-$ to $1000-\mathrm{GeV}$ decade as well as the rise time of $8.7 \pm 2.0$ years of the colliding-beam machines (Fig. 5 and Table II).

If nuclear physics experiments, as well as HEP experiments, are included with the papers of the $100-\mathrm{MeV}$ to $1-\mathrm{GeV}$ decade, then for papers written after 1956 the decay time for the use of accelerators in this decade increases from $6.5 \pm 4$ years to $10 \pm 1$ year. This longer decay time is characteristic not only 
of the decay time of $13.5 \pm 2.0$ and $11.2 \pm 2.5$ years for the use of accelerators in the 1 - to $10-\mathrm{GeV}$ and the $10-$ to $100-\mathrm{GeV}$ decades, respectively, but also of the rise times mentioned above.

As a peripheral observation, the rise in raw number of papers per year in each of the energy decades is linear with a similar slope of roughly 18 papers per year (Fig. 1 and Table III). Furthermore, the number of authors per paper shows exponential growth with a doubling time of 12 years (Fig. 2). Such an increase is to be expected because as the complexity of experiments increases, the manpower required to build and operate the equipment must likewise increase. Surprisingly, however, the number of authors is almost independent of the machine on which the experiment was performed, with the exception that in experiments done on the colliding-beam machines, twice the number of authors took part.

B. Instrumentation Usage

Experimental techniques were divided into six categories: counters only, emulsion stack, cloud chamber, bubble chamber, spark chamber, and MWPC plus drift chamber.

Many types of counters have been in use, employing solid scintillator, liquid scintillator, lead glass, and solid-state detectors. These types were all put into the class of counters only.

Although experiments with cloud, spark, or drift chambers need accompanying counters to trigger or to define a start time, these experiments were classified according to the chamber used. Often, many different types of chambers were used. In these cases, the classification referred to the chamber incorporating the latest technology.

A later development of the bubble chamber was the hybrid chamber, where data from counters and MWPCs were used in conjunction with the chamber. These hybrid experiments were classified as bubble-chamber experiments.

In the above natural grouping, logistic behavior is observed (Fig. 6).

It is seen that the counters only play a passive role in the evolution of instrumentation, with their use falling at the rate of $30 \pm 2.6$ years from 1952 to the present (Table IV). Although counters are capabie of handling data electronically at high rates, the number of elements necessary to resolve individual tracks in high-energy collisions, coupled with the high cost of the associated photomultiplier tube relative to other instrumentation, has limited their sole use.

The cloud chamber and the emulsion stack, on the other hand, can each be used to observe individual tracks in complex interactions. The cloud chamber has a long resolving time, however, and the emulsion stack is tedious to scan. The bubble chamber overcomes these difficulties. Figure 7 shows that only $2.2 \pm 0.2$ years were required for this technique to replace that of the cloud chamber and that of the emulsion stack.

The main disadvantage of the bubble chamber is its inability to be triggered. The optical spark chamber (OSC) by-passes this limitation. A system of spark chambers, however, cannot easily cover the large solid angle that the bubble chamber can. Furthermore, by their nature they are prone to electrical deterioration, just as spark plugs in an automobile are, so constant maintenance is required. In addition, the burden of scanning film still remalns.

The time-consuming problem of film scanning was eliminated by the developmental of the wire spark chamber (WSC). These chambers usually employ a magnetostrictive readout system. They are simple and inexpensive to construct, and they give excellent spatial resolution. Other types of electronic readout chambers were developed, such as the sonic chamber. They account for only a 
small fraction of the electronic chambers used and accordingly were grouped with the WSCs.

The rate-limitation and maintenance problems inherent in spark chambers were eliminated by the introduction of the MWPC. Unfortunately, this instrument is expensive, because spatial resolution is defined by the pitch of the sense wires, and each wire requires an individual amplifier. This disadvantage was lessened by using fewer wires and simultaneously measuring the drift time required for the primary ions, created by the traversal of a charged particle, to arrive at the sense wire.

As indicated in Figs. 7 and 8 , the WSC replaced the OSC at the rate of $7.4 \pm 0.7$ years, the MWPC and drift chamber replaced the OSC and WSC at the rate of $4.2 \pm 0.4$ years, and the drift chamber is now replacing the MWPC at the rate of $4.2 \pm 1.7$ years. Interestingly, despite the fact that each of these triggerable systems was developed at different times and at different rates, the overall replacement of the bubble chamber by these systems proceeded at the constant rate of $8.6 \pm 0.2$ years from 1960 to the present (Fig. 9).

Figure 10 illustrates that $f$ does not grow exponentially, but rather that it behaves in a way representative of the differential equation given above.

\section{CONCLUSIONS}

This brief study demonstrates that the logistic-substitution model can be adapted to describe the use of different accelevators and experimental techniques by American physicists.

Specifically, once the decline in the use of cyclotrons with respect to proton synchrotrons set in, the decline continued at the same initial rate. This rate of decline was independent of the introduction of the alternating-gradient synchrotron, which in turn replaced the proton synchrotron. Similar observations are noted in the use of different experimental techniques. For example, once the decline in the use of the bubble chamber with respect to the OSC set in, the rate of decline also proceeded at a constant rate independent of the introduction of the WSC, the MWPC, or the drift chamber.

The constant rate of decline in the use of these machines or techniques with respect to their newer counterparts, over three orders of magnitude in the variable $f /(1-f)$, provides impressive confirmation of the basic assumption of the model. This assumption is simply that the fractional usage $f$ behaves exponentially when normalized to 1 - $f$; the latter term takes into account the unitarity constraint that $f$ can never exceed $100 \%$.

To answer the question relating to patterns, the study revealed that roughly 10 years characterizes the rise and decay times for the use of machines in the various energy decades. The utilization of individual accelerators, however, peaks just 6 years after construction is completed, and their use declines from $50 \%$ to $10 \%$ in about 14 years.

With respect to instrumentation, no general pattern emerges. Here, rise and decay times vary by an order of magnitude. For example, in just over two years the bubble chamber replaced the cloud chamber and the emulsion stack as a means for observing particles in high-energy collisions. On the other hand, $12 \pm 1$ years were required for the various triggerable systems to reduce the usage of this powerful instrument from $50 \%$ to $10 \%$.

Lastly, consider the question relating to future trends. Because of the uncertainty as to when and at what rate a new accelerator or experimental technique will be developed, it is not possible, from these data to predict when the use of an accelerator or technique that is at present expanding in use will 
begin to decline. However, once the decline has set in, this study shows that it is reasonable to expect the decline to continue.

\section{ACKNOWLEDGMENTS}

I would like to thank R. Hagedorn for bringing the work of C. Marchetti to my attention by his introduction of $C$. Marchetti to the CERN community at the Gregory Memorial Lecture of November 1980. I thank also W. Blum, R. Hagedorn, and P. Palazi for many stimulating discussions concerning the contents of this paper. Thanks also to Lilly Cordova for typing this report.

\section{REFERENCES}

1. C. Marchetti, "Primary Energy Substitution Models: On the Interaction Between Energy and Society," Tech. Forecast. Soc. Change 10, 345-356 (1977).

2. C. Marchetti and N. Nakicenovic, "The Dynamics of Energy Systems and the Logistic Substitution Mode1," RR-79-13, International Institute for Applied Systems Analysis, Laxenburg, Austria (December 1979).

3. C. Marchetti, "On Energy Systems in Historical Perspective," 1980 Bernard Gregory Memoria1 Lecture, CERN, November 1980.

4. J. C. Fischer and R. H. Pry, "A Simple Substitution Model of Technologica1 Change," Tech. Forecast. Soc. Change 3, 75-88 (1971-1972).

5. M. S. Livingston and J. P. Blewett, "Particle Accelerators," (McGraw-Hil1 Book Co., New York, 1962), pp. 6, 194, 329, 354, 401, and 445.

6. F. T. Howard, "Cyclotrons and High-Energy Accelerators - 1958," Oak Ridge National Laboratory report ORNL-2644 (November 1958).

7. M. Q. Barton, "Catalogue of High-Energy Accelerators," Brookhaven National Laboratory report BNL 683 (T-230) (September 1961).

8. F. T. Howard, "High-Energy Accelerators - 1967," Oak Ridge Nationa1 Laboratory report ORNLAIC-1 (November 1967).

9. J. H. B. Madsen and P. H. Standley, "Catalogue of High-Energy Accelerators," CERN (July 1980). 
TABLE I

ACCELERATORS GROUPED IN FIVE CLASSES

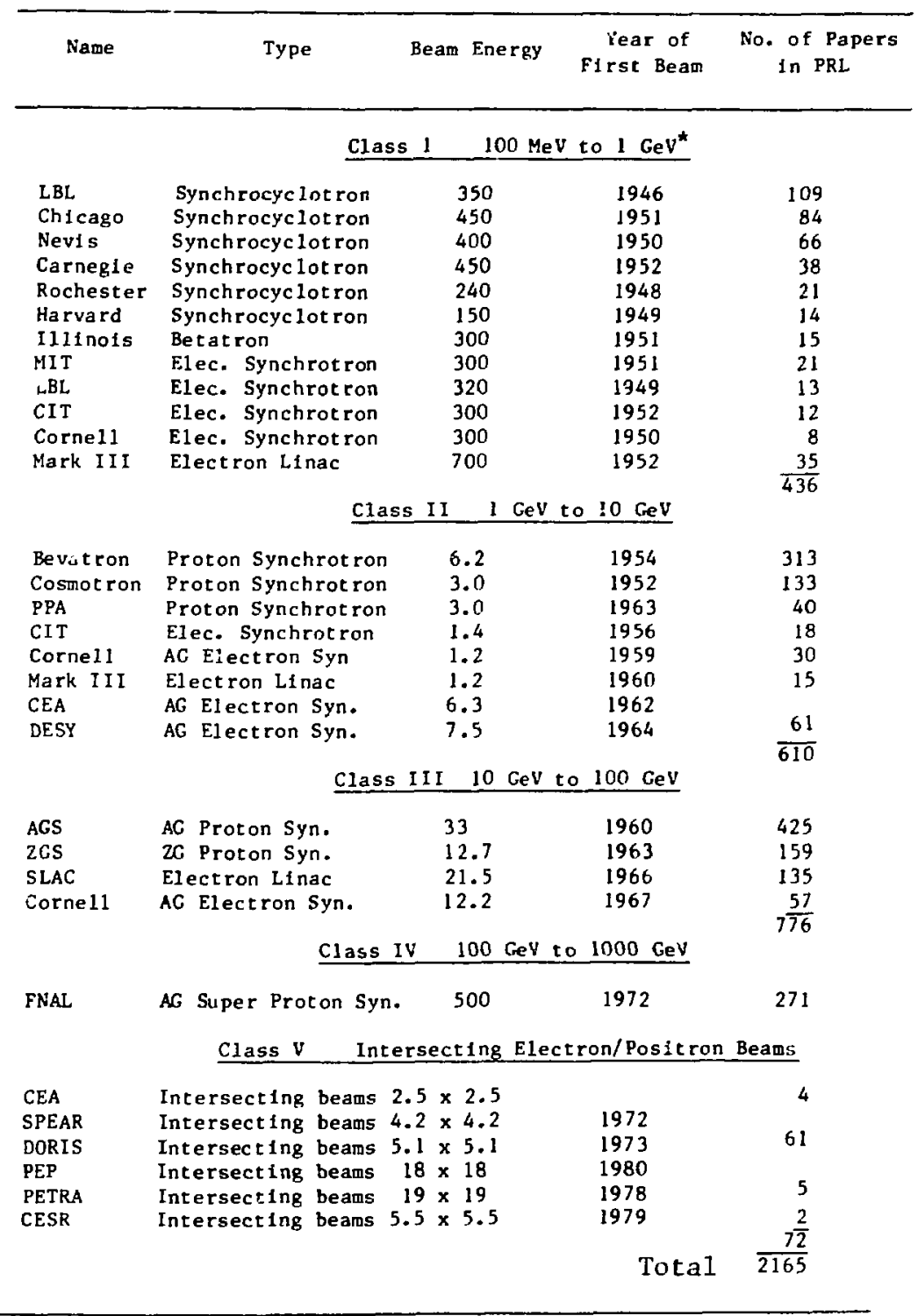

*The high-intengity machines of this class--such as LAMPF, SIN, and TRIUMF-forge frontiers of rare processes. They were constructed in the 1970 s and, as such, were not included. 
TABLE II

RESULTS OF FITS TO ALCELERATOR USAGE

\begin{tabular}{|c|c|c|c|c|c|}
\hline Machine & $\begin{array}{l}\text { Time } \\
\text { Period } \\
\text { (year) }\end{array}$ & $\begin{array}{c}\text { Approximate Time } \\
\text { from First Beam } \\
\text { to Peak } \\
\text { (year) }\end{array}$ & $\begin{array}{c}\text { Decay Time } \\
\text { (year) }\end{array}$ & $x^{2}$ & $\begin{array}{l}\text { Number } \\
\text { or DOF }\end{array}$ \\
\hline $\begin{array}{l}100 \mathrm{MeV} \text { to } 1 \mathrm{GeV} \\
\mathrm{HEP} \text { papers only }\end{array}$ & $1953-1969$ & & $6.5 \pm 0.5$ & 5.7 & 7 \\
\hline Bevatron & $1959-1971$ & 5 & $12.6 \pm 0.6$ & 1.3 & 5 \\
\hline AGS & $1967-1979$ & 6 & $16.1 \pm 0.9$ & 2.9 & 5 \\
\hline ZGS & $1971-1979$ & 8 & $15.4 \pm 5.7$ & 2.7 & 3 \\
\hline SLAC & $1971-1979$ & 5 & $18.0 \pm 3.6$ & 2.0 & 3 \\
\hline Cornel1 $12 \mathrm{GeV}$ & $1973-1979$ & 6 & $21.0 \pm 15.0$ & 0.9 & 2 \\
\hline
\end{tabular}

\begin{tabular}{|c|c|c|c|c|c|}
\hline Energy Decade & $\begin{array}{l}\text { Time } \\
\text { Period } \\
\text { (year) }\end{array}$ & $\begin{array}{l}\text { Rise 'Time } \\
\text { (year) }\end{array}$ & $\begin{array}{c}\text { Decay Time } \\
\text { (year) }\end{array}$ & $x^{2}$ & $\begin{array}{l}\text { Number } \\
\text { of DOF }\end{array}$ \\
\hline $\begin{array}{l}100 \text { Mev to } 1 \mathrm{GeV} \\
\text { A1l papers }\end{array}$ & $1957-1977$ & & $10.0 \pm 1.0$ & 14.9 & 9 \\
\hline 1 to $10 \mathrm{GeV}$ & $\begin{array}{l}1953-1957 \\
1961-1971\end{array}$ & $4.8 \pm 0.7$ & $13.5 \pm 2.0$ & $\begin{array}{l}0.4 \\
0.9\end{array}$ & $\begin{array}{l}1 \\
4\end{array}$ \\
\hline 10 to $100 \mathrm{GeV}$ & $\begin{array}{l}1963-1969 \\
1971-1979\end{array}$ & $11.1 \pm 2.0$ & $11.1 \pm 2.5$ & $\begin{array}{l}0.2 \\
4.1\end{array}$ & $\begin{array}{l}2 \\
3\end{array}$ \\
\hline $\begin{array}{l}100 \text { ro } 1000 \mathrm{GeV} \\
\mathrm{e}^{+} \mathrm{e}^{-}\end{array}$ & $\begin{array}{l}1973-1977 \\
1973-1979\end{array}$ & $\begin{array}{l}9.3 \pm 2.2 \\
8.7 \pm 2.0\end{array}$ & & $\begin{array}{l}0.2 \\
8.0\end{array}$ & $\begin{array}{l}2 \\
2\end{array}$ \\
\hline
\end{tabular}


TABLE III

RESULTS OF FITS TO THE NUMBER OF PAPERS PER YEAR

\begin{tabular}{|l|c|c|c|c|}
\hline Energy Decade & $\begin{array}{c}\text { Tim } \\
\text { Period } \\
\text { (GeV) }\end{array}$ & $\begin{array}{c}\text { Number of Papers } \\
\text { per Year }\end{array}$ & $x^{2}$ & $\begin{array}{c}\text { Number } \\
\text { of DOF }\end{array}$ \\
\hline 1 to 10 & $1953-1957$ & $21.1 \pm 2.5$ & 2.9 & 1 \\
10 to 100 & $1961-1969$ & $17.9 \pm 1.1$ & 2.5 & 3 \\
100 to 1000 & $1971-1977$ & $17.1 \pm 1.2$ & 1.9 & 2 \\
\hline
\end{tabular}

TABLE IV

RESULTS OF FITS TO INSTRUMEN'TATION USAGE

\begin{tabular}{|l|r|r|r|c|}
\hline \multicolumn{1}{|c|}{ Techni jues being Compared } & $\begin{array}{r}\text { Tim. } \\
\text { Period }\end{array}$ & Rise Time & $x^{2}$ & $\begin{array}{c}\text { Number } \\
\text { of DoF }\end{array}$ \\
\hline Bubble vs (cloud + emulsion) & $1955-1961$ & $2.2 \pm 0.2$ & 2.3 & 2 \\
(Spark + MWPC + dwift) vs bubblear) & $1961-1979$ & $8.6 \pm 0.2$ & 7.6 & 8 \\
(MWPC + drift) vs spark & $1971-1979$ & $4.2 \pm 0.4$ & 3.1 & 3 \\
Wire spark vs optical spark & $1965-1977$ & $7.4 \pm 0.7$ & 5.1 & 5 \\
Drift vs MWPC & $1977-1979$ & $4.2 \pm 1.7$ & 0.0 & 0 \\
Counters only & & Decay Time & & \\
Bubble chamber & $1953-1979$ & $30.0 \pm 2.6$ & 13.0 & 12 \\
\hline
\end{tabular}




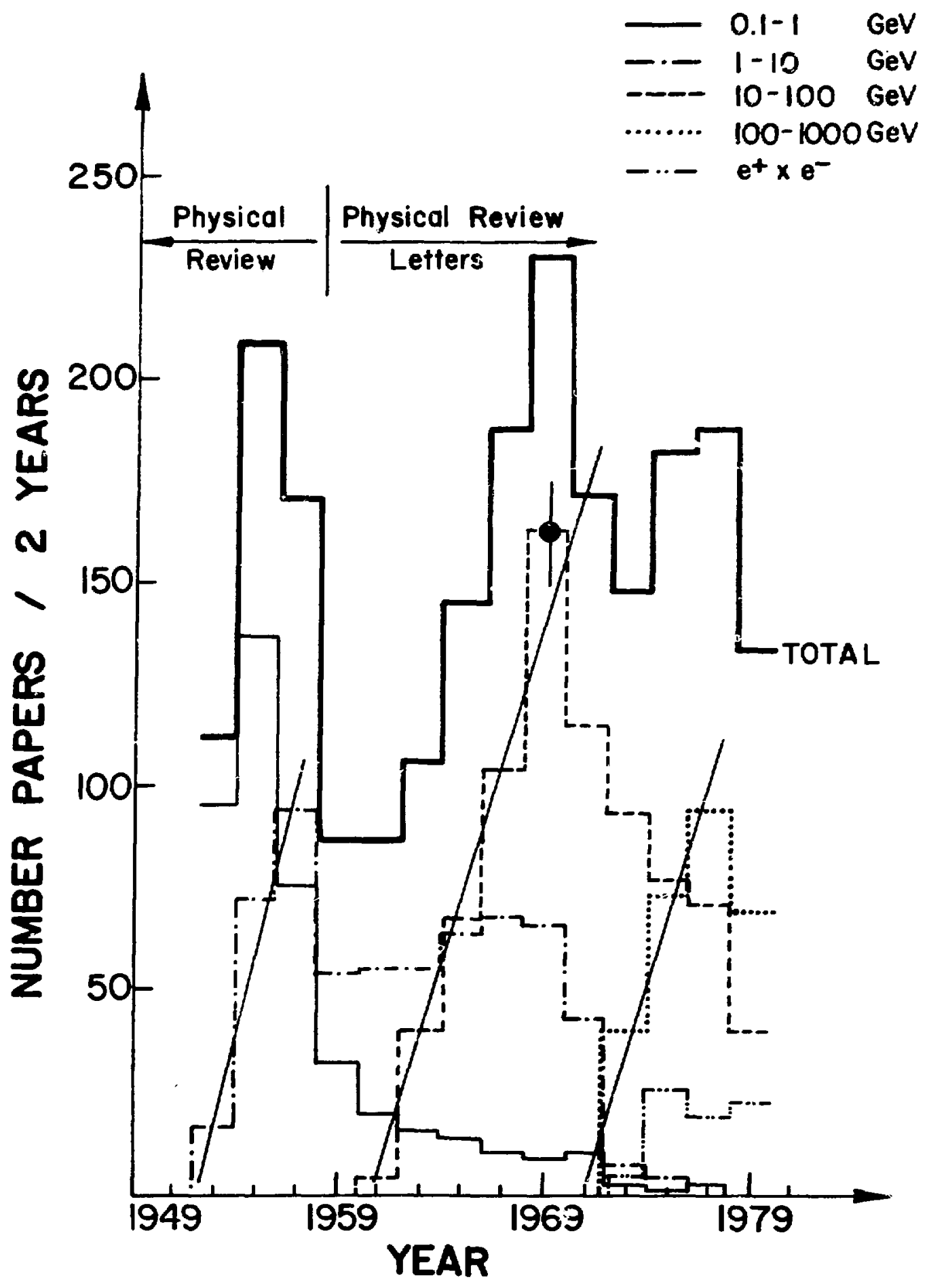

Fig. 1. Number of papers versus year and energy decade. 


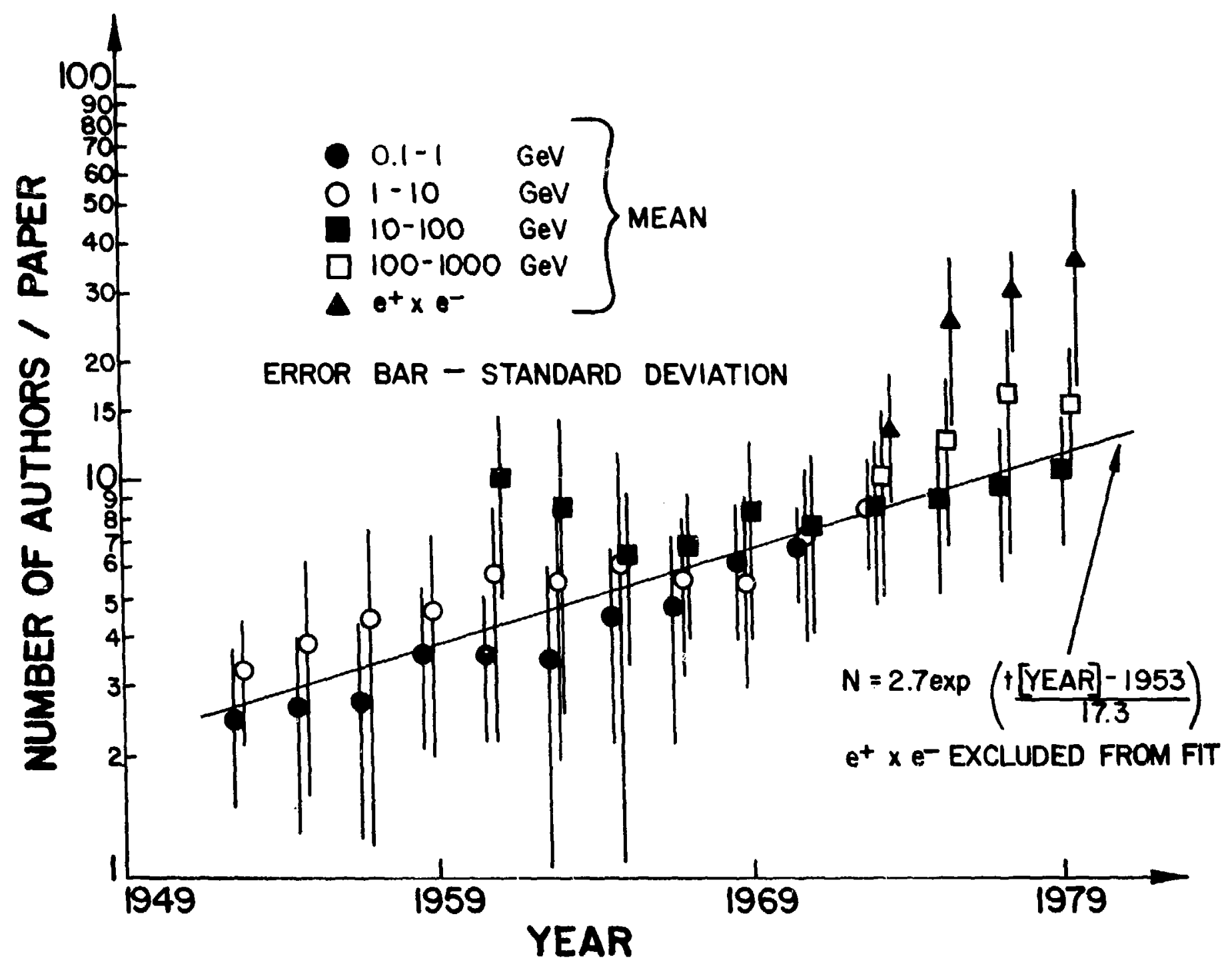

Fig. 2. Number of authors per paper versus year and energy class. 


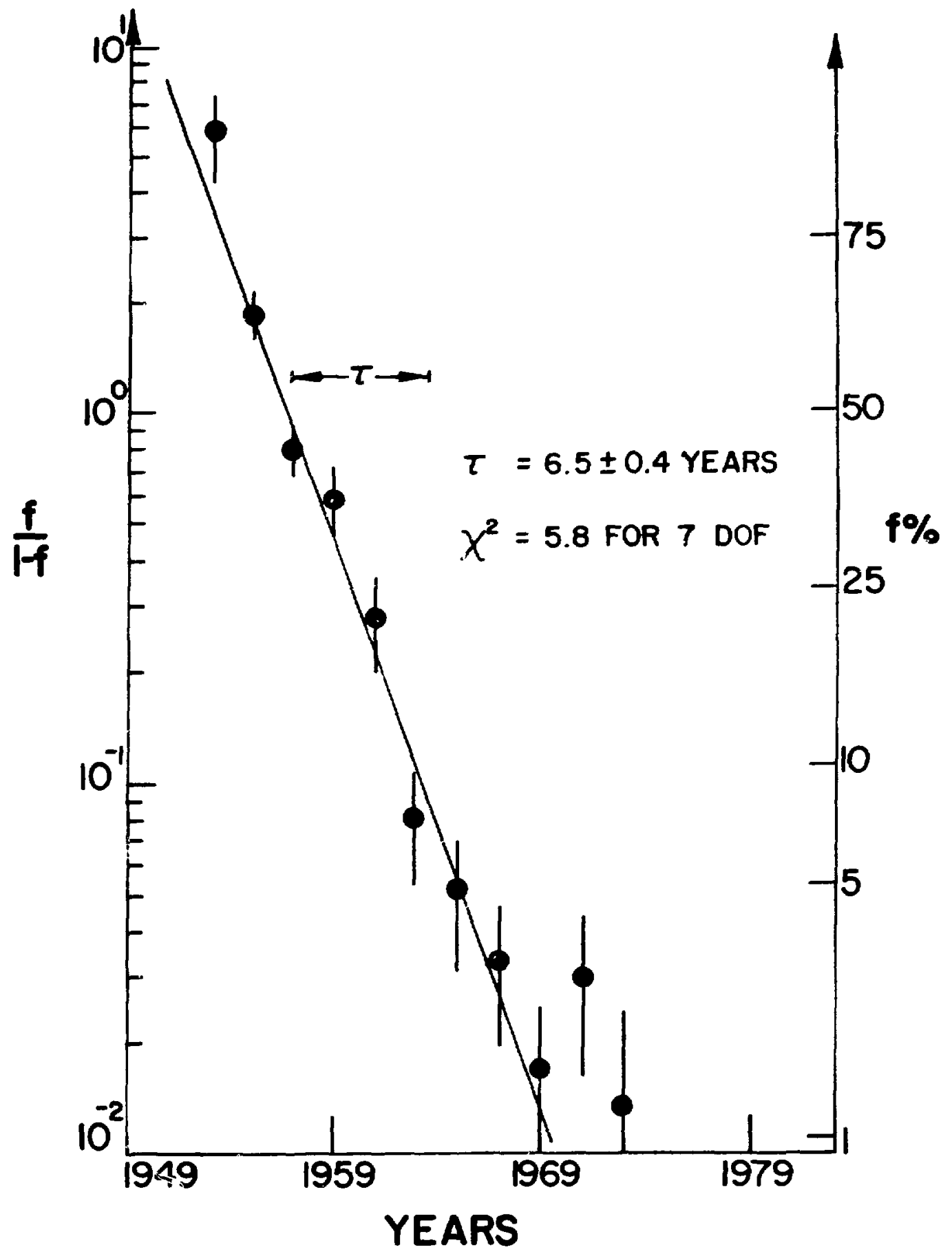

Fig. 3. Use of accelerators in the $100-\mathrm{MeV}$ to $1-\mathrm{GeV}$ energy decade. 


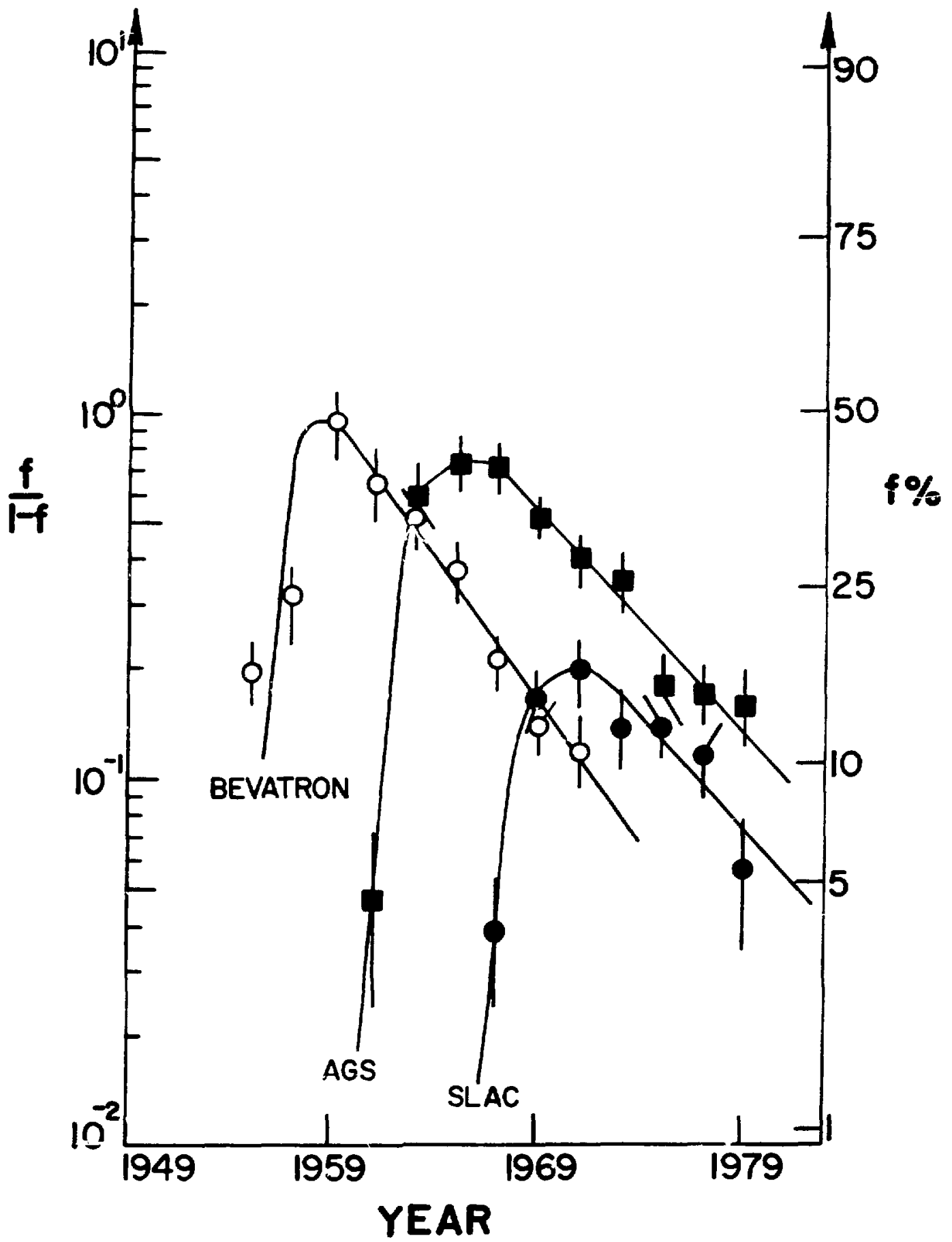

Fig. 4. Use of individual accelerators. 


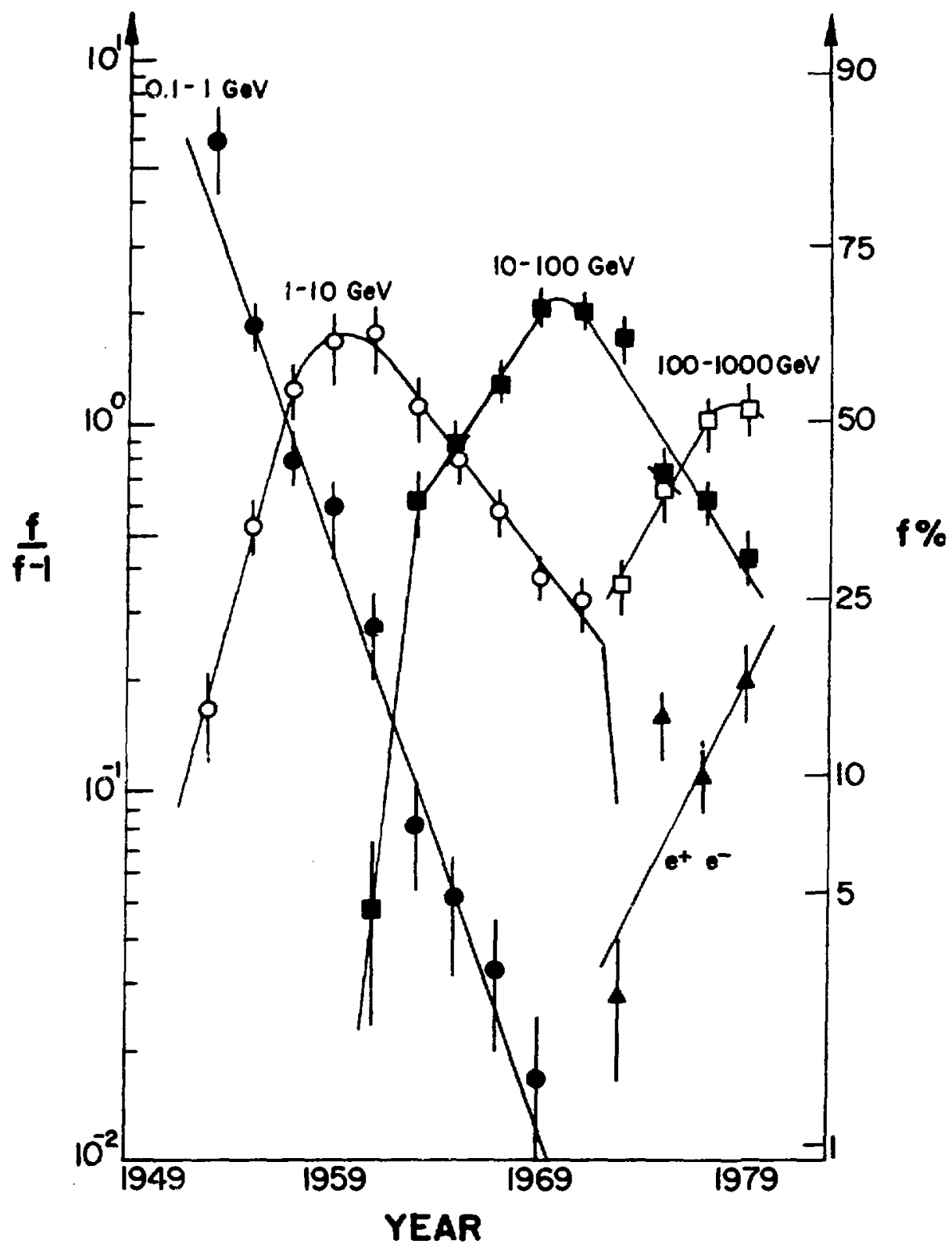

Fig. 5. Use of accelerators in five energy classes. 


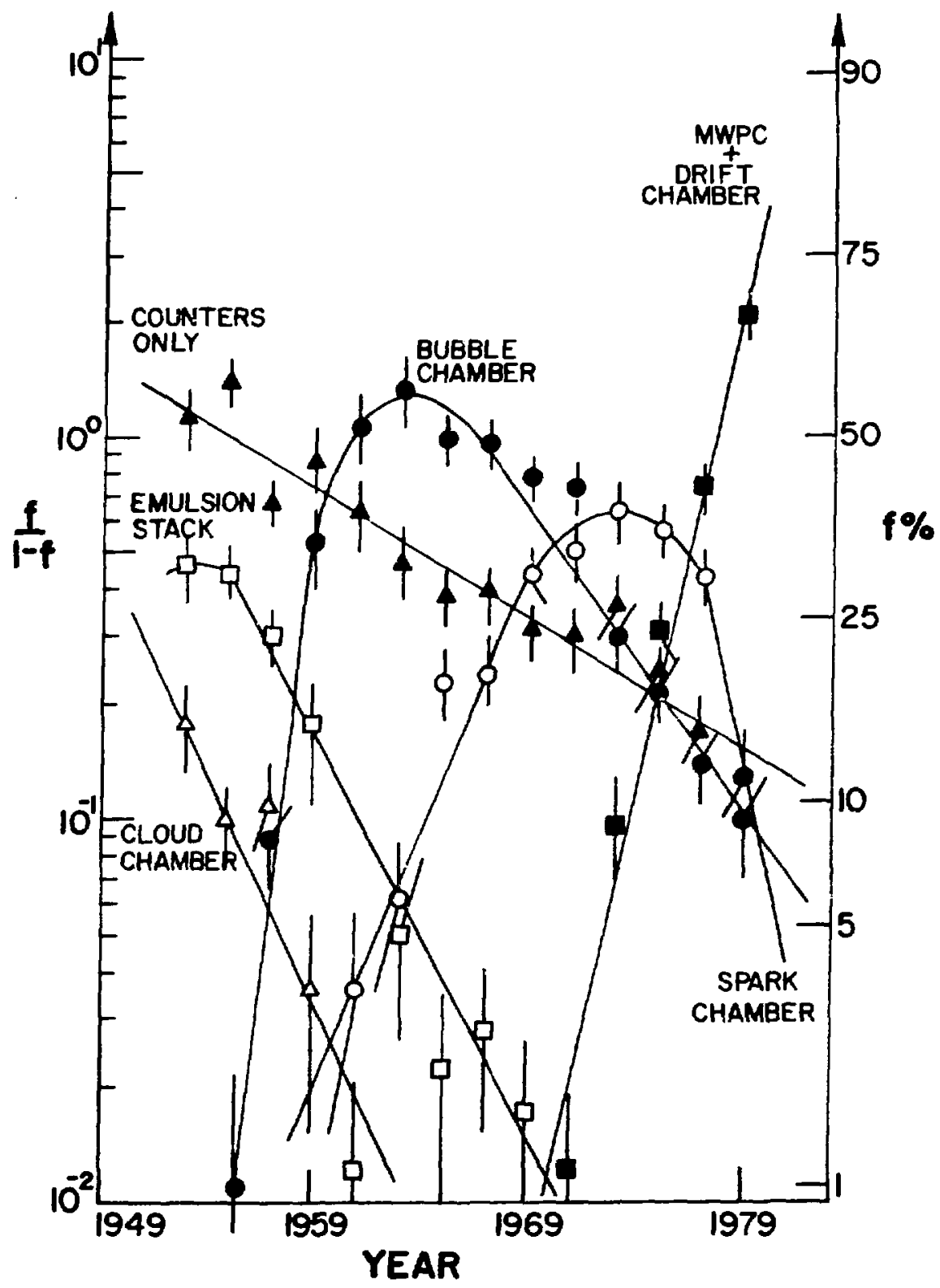

Fig. 6. Use of six different experimental techniques. 


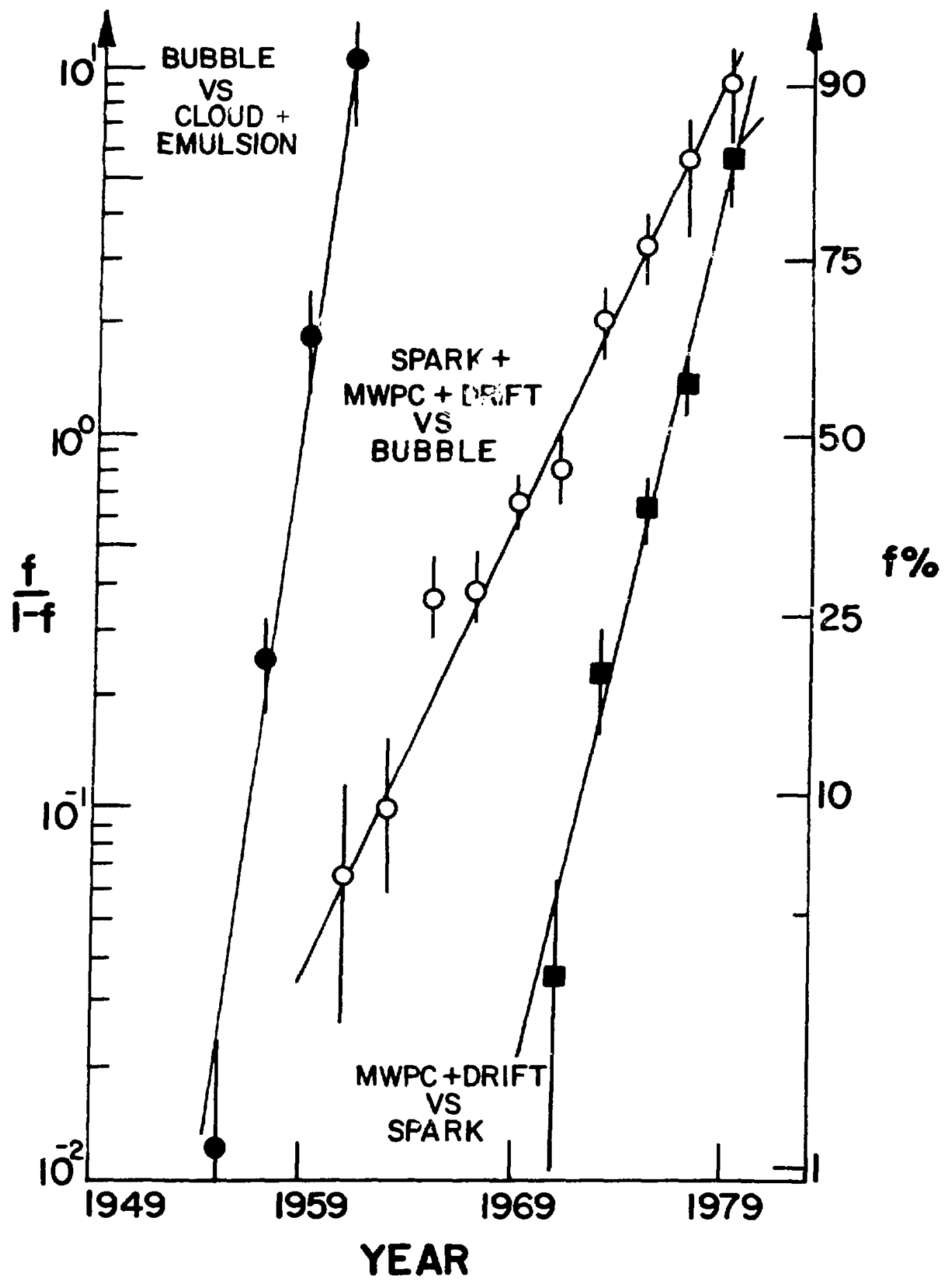

Fig. 7. Use of new versus old experimental techniques. 


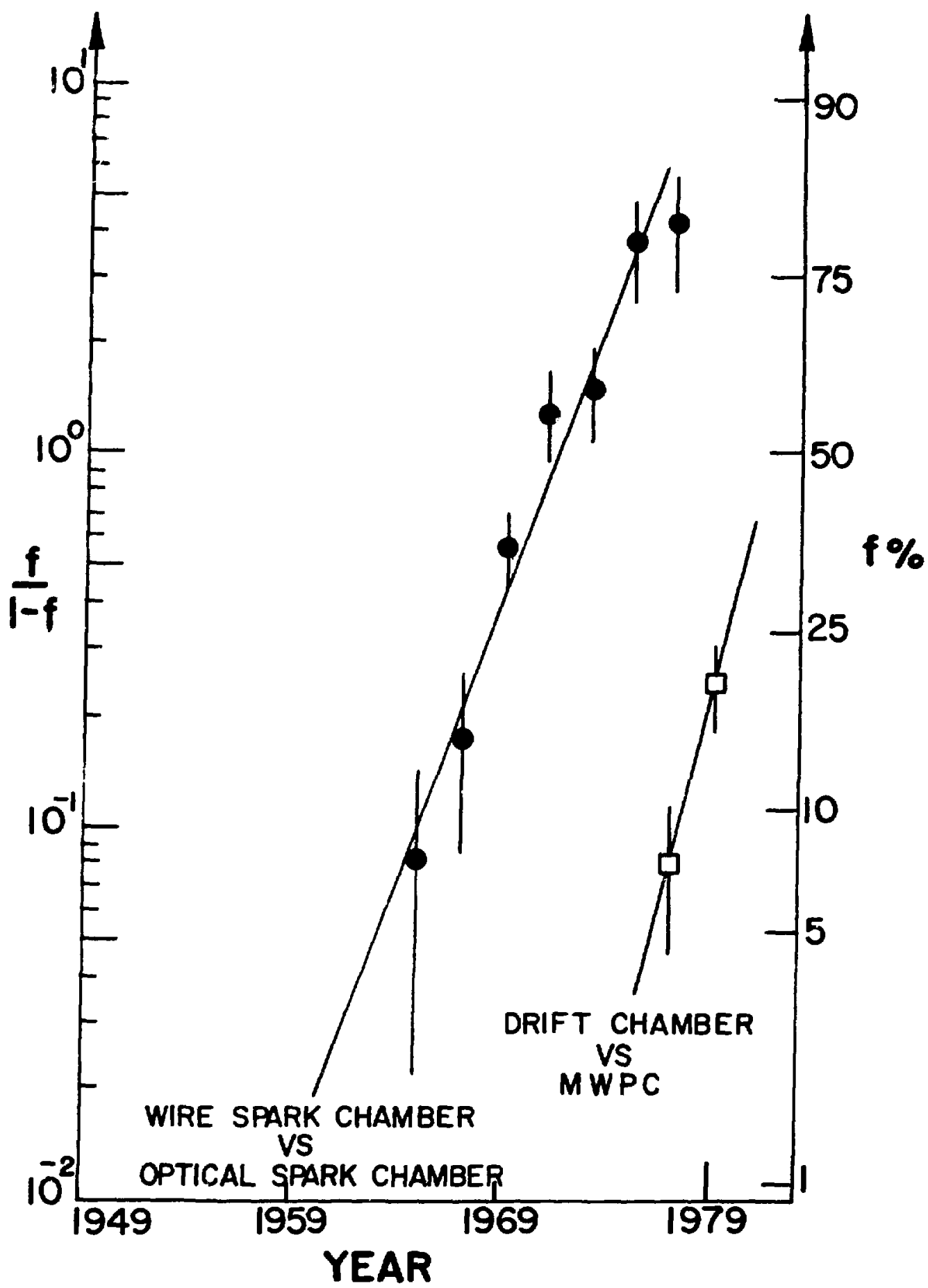

Fig. 8. Use of the WSC versus the OSC and use of the drift chamber versus the MWPC. 


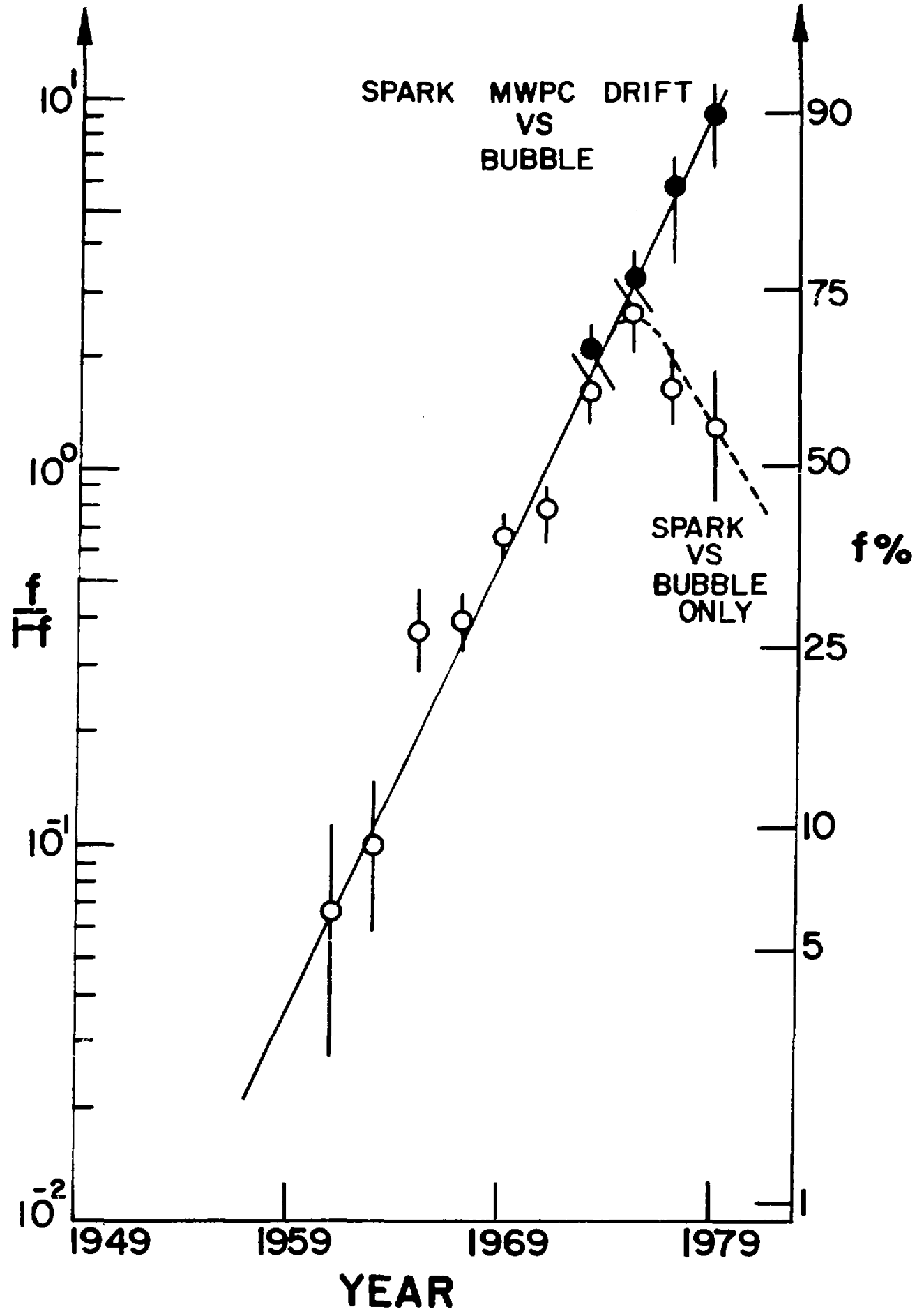

Fig. 9. Use of the spark chamber, MWPC, and drift chamber versus the bubble chamber. 


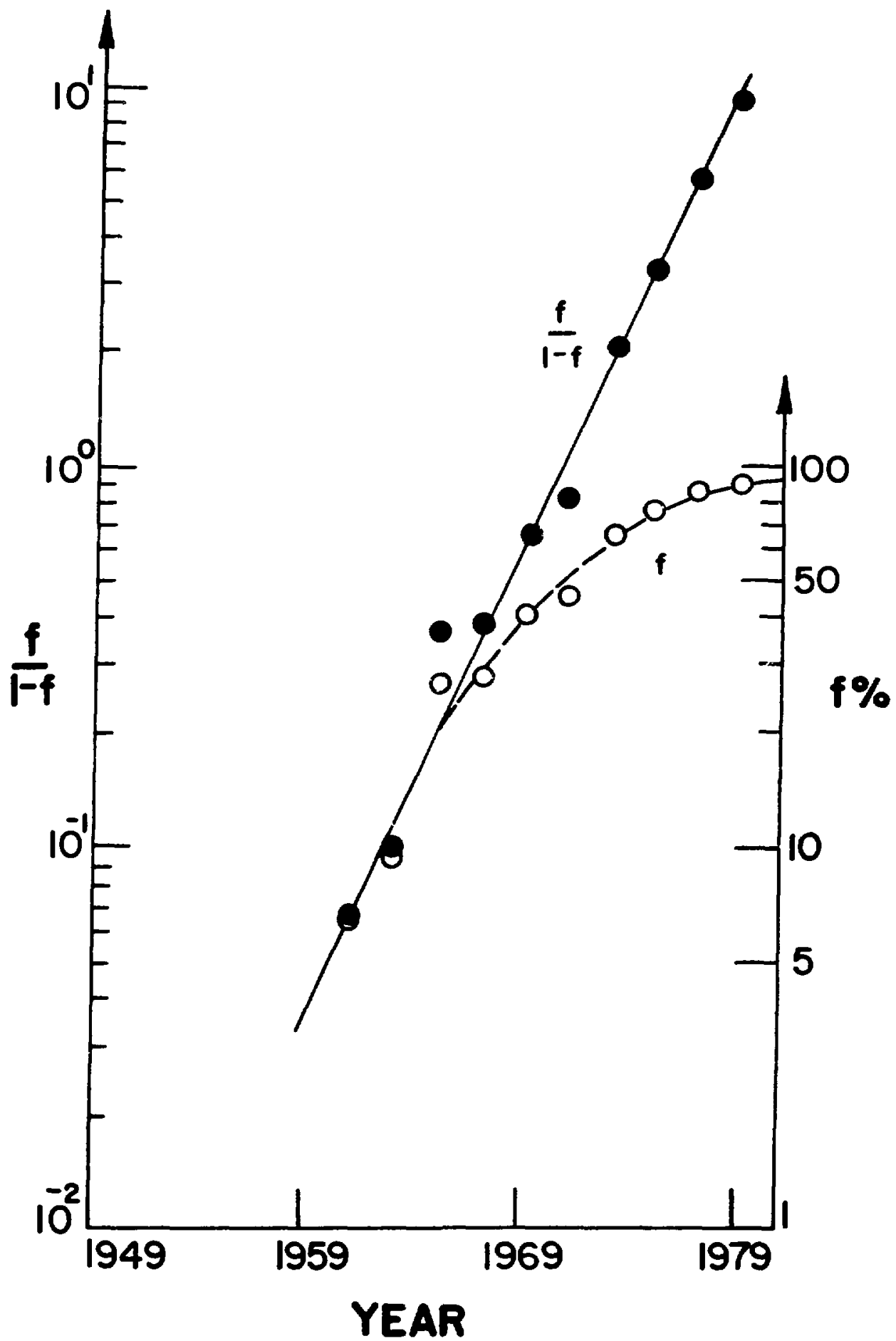

Fig. 10. Comparison of $f$ and $f / 1$ - $f$ for the use of spark chambers, MWPC, and drift chambers versus the bubble chamber. 